\title{
sciendo
}

\author{
BULGARIAN ACADEMY OF SCIENCES
}

CYBERNETICS AND INFORMATION TECHNOLOGIES • Volume 20, No 6

Special Issue on New Developments in Scalable Computing

Sofia • 2020

Print ISSN: 1311-9702; Online ISSN: 1314-4081

DOI: $10.2478 /$ cait-2020-0070

\section{Degree-Day Climatology over Central and Southeast Europe for the Period 1961-2018 - Evaluation in High Resolution}

\author{
Hristo Chervenkov ${ }^{1}$, Vladimir Ivanov ${ }^{2}$, Georgi Gadzhev ${ }^{2}$, Kostadin \\ Ganev $^{2}$, Dimitrios Melas ${ }^{3}$ \\ ${ }^{1}$ National Institute of Meteorology and Hydrology (NIMH), Tsarigradsko Shose Blvd. 66, 1784 Sofia, \\ Bulgaria \\ ${ }^{2}$ National Institute of Geophysics, Geodesy and Geography - Bulgarian Academy of Sciences (NIGGG- \\ BAS), Acad. Georgi Bonchev Str., Bl. 3, 1113 Sofia, Bulgaria \\ ${ }^{3}$ Aristotle University of Thessaloniki Faculty of Sciences School of Physics, Thessaloniki, 54124, Greece \\ E-mails: hristo.tchervenkov@meteo.bg vivanov@geophys.bas.bg \\ ggadzhev@geophys.bas.bg_kganev@geophys.bas.bg melas@auth.gr
}

\begin{abstract}
The ongoing climate change over Central and Southeast Europe has a great potential to affect significantly the public energy demands and in particular the energy consumption in the residential heating and cooling sector. The linkage of the ambient daily extreme and mean temperatures and the energy needs for condition or heat buildings can be quantified as numerical indicators as the heating and cooling degree-days. In the present study, these indicators are calculated according the UK Met Office methodology from the daily mean and extreme temperatures, which, in turn, are computed from the output of the MESCAN-SURFEX system in the frame the FP7 UERRA project. The study, which is performed in a very high resolution, is dedicated on the analysis of the spatial patterns as well as assessment of the magnitude and statistical significance of the temporal evolution of the heating and cooling degree-days. It reveals general tendencies which are coherent with the regional climate warming, but with high spatial heterogeneities. The study confirms the essential impact of the ongoing climate change on the heating, ventilating and air-conditioning industry over Central and Southeast Europe.
\end{abstract}

Keywords: Degree-days, MESCAN-SURFEX, UERRA Project, trend analysis.

\section{Introduction}

According to the high-level synthesis report of the United Nations, titled "United In Science" (https://public.wmo.int/en/resources/unitedinscience), the climate change is the defining challenge of our time which exert influence on the ecosystems, on all branches of the international economy, and on the quality of life. The globally 
averaged surface temperature of the Earth increased $0.85{ }^{\circ} \mathrm{C}$ over the 1880 to 2012 period [19]. The global warming effects and the associated regional climatic changes over Central and Southeast Europe (CSE) have been widely documented in the last decades based on in situ measurements $[1,3,16]$, assimilated surface observations $[6,9,14,22-24]$, reanalysis [11] global $[10,26]$ and regional climate models $[5,19,20]$. Most of these studies are focused on the second half of the twentieth and the first decade of the 21 st century, clearly evidencing that, similarly to the global and continental trends, the regional temperature got warmer during the period. The study of near past climate provides an essential baseline from which to understand and contextualize changes in the contemporary and future climate.

As evidenced in many recent publications (e.g., [7, 21, 28]), the changes in climate have direct and indirect impact on managed systems like heating, ventilating and air-conditioning industry. Space heating and cooling is responsible for a large fraction of European energy use [18]. The linkage of the ambient daily extreme and mean temperatures and the energy needs for air-conditioning or heat buildings can be quantified as numerical indicators as the Heating Degree-Days (HDD) and Cooling Degree-Days (CDD). Thus, HDD and CDD are rough surrogates for how climate change is likely to affect energy use for heating and cooling. In the present study, these indicators are calculated according the UK Met Office (UKMO) methodology from the daily minimum, mean and maximum temperatures, denoted $\mathrm{tn}, \mathrm{tg}$ and $\mathrm{tx}$ respectively, which, in turn, are computed from the output of the MESCAN-SURFEX system in the frame the FP7 UERRA project. The study, which is performed in a very high resolution, is dedicated on the analysis of the spatial patterns as well as on the assessment of the magnitude and statistical significance of the temporal evolution of the HDD and CDD over CSE Europe.

The article is structured as follows. The used input data are described in Section 2 titled "Short Description of UERRA and MESCAN-SURFEX". A brief explanation of the UKMO definition of the HDD and CDD is placed in Section 3. The core of the article is Section 4, containing 2 subsections and titled "Performed Calculations and Obtained Results". The concluding remarks are in Section 5.

\section{Short description of UERRA and MESCAN-SURFEX}

Accurate and reliable sources of information are crucial for building energy simulations and analyses [7] and thus we have exploited modern and reliable weather data in a very high spatial resolution.

The objective of the project-driven collaborative initiative FP7 UERRA (Uncertainties in Ensembles of Regional ReAnalyses (RRA); www.uerra.eu) is to produce ensembles of European RRA of essential climate variables for several decades and estimate the associated uncertainties in the data sets [25, 30]. It also includes recovery of historical (last century) data and creation of user friendly data services. Within UERRA three different Numerical Weather Prediction (NWP) models have been employed to generate European RRA and subsequent surface reanalysis products. 
The MESCAN-SURFEX system analysis uses the 2D-analysis system MESCAN [27] and the land surface platform SURFEX [4] to generate a coherent surface and soil analysis. The UERRA-NWP HARMONIE-ALADIN at $11 \mathrm{~km}$ grid spacing is used as a starting point to further downscaling. Beside the other parameters, MESCAN-SURFEX produces air temperature at $2 \mathrm{~m}$ above the surface in 6-hour temporal resolution, i.e., at 00, 06, 12 and 18 UTC for the period 1961-2018. Based on the availability of this data, the tn, tg and tx are derived in regular $0.05^{\circ} \times 0.05^{\circ}$ grid and validated against independent data sets as documented in [12].

The applicability of the derived in such fashion temperature data for assessment of agro-meteorological indices over CSE Europe in the context of climate change is demonstrated in [13].

\section{HDD and CDD}

HDD and CDD are, similarly to the climate and agro-meteorological indices [1], an attempt to objectively extract information from daily weather data (observations or model as in current study) that answers questions concerning energy demand and/or consumption in the residential and domestic heating and cooling sector. Thus, they are likely to display the same types of variability as the temperature data on which they are based. The heating and cooling requirements for a given structure at a specific location are considered, beside the impact of the other factors, proportional to the number of HDDs and CDDs at that location [7]. Recently, many studies have focused on the use of HDD and CDD to estimate annual and seasonal trends in the energy demand for heating and cooling residential, commercial, and industrial buildings, especially in the context of climate change (see [21, 28,29] and references therein). Hence, the theoretical formulation of both indicators is not standardised, their computation can be performed in different ways, depending on the nature and scope of the study as well as availability of input data. Computation methods range from simple models based on monthly or annual temperature to more sophisticated approaches [28, 29]. In the present study we use the developed by the UKMO [15] and successfully applied in [29] method. According it, daily HDD and CDD are calculated based on a comparison of $\mathrm{tn}, \mathrm{tg}$ and $\mathrm{tx}$ with the selected base temperature (tb), taking account of fluctuations of daily air temperature around the base temperature, as well as the asymmetry between daily mean temperature and diurnal temperature variations, as shown on Table 1.

Table 1. UKMO methodology for computing daily HDD and CDD

Table 1 . UKMO methodology for computing daily HDD and CDD
\begin{tabular}{|c|c|c|}
\hline Condition & HDD & CDD \\
\hline $\mathrm{tx} \leq \mathrm{tb}$ (uniformly cold day) & $\mathrm{HDD}=\mathrm{tb}-\mathrm{tg}$ & $\mathrm{CDD}=0($ No cooling is required $)$ \\
\hline $\mathrm{tg} \leq \mathrm{tb}<\mathrm{tx}$ (mostly cold day) & $\mathrm{HDD}=(\mathrm{tb}-\mathrm{tn}) / 2-(\mathrm{tx}-\mathrm{tb}) / 4$ & $\mathrm{CDD}=(\mathrm{tx}-\mathrm{tb}) / 4$ \\
\hline $\mathrm{tn}<\mathrm{tb}<\mathrm{tg}$ (mostly warm day) & $\mathrm{HDD}=(\mathrm{tb}-\mathrm{tn}) / 4$ & $\mathrm{CDD}=(\mathrm{tx}-\mathrm{tb}) / 2-(\mathrm{tb}-\mathrm{tn}) / 4$ \\
\hline $\mathrm{tn} \geq \mathrm{tb}$ ( uniformly warm day) & $\mathrm{HDD}=0$ (No heating is required) & $\mathrm{CDD}=\mathrm{tg}-\mathrm{tb}$ \\
\hline
\end{tabular}

Hence, as the study is on annual basis, we summed up the daily values. The base temperature is the outdoor temperature below or above which heating or cooling is 
needed [7]. As in the original proposal [15], tb is set on $15.5{ }^{\circ} \mathrm{C}$ for the HDDcomputation and on $22.0^{\circ} \mathrm{C}$ for the $\mathrm{CDD}$-computation. Previous versions of these indicators, based solely on tg, have a jump discontinuity when daily mean temperature falls below the base temperature. UK Met Office methodology does not exhibit such a discontinuity [18]. It is worth to emphasize also, that in present work the daily mean temperature is independent input parameter, rather than estimated as arithmetic average between tn and tx as in [28, 29].

The units of measurement of the HDD and CDD are degree-days, noted further ${ }^{\circ} \mathrm{D}$ as properly proposed in [21].

\section{Performed calculations and obtained results}

\subsection{Spatial patterns and temporal evolution}

First, in order to reveal long term inter-annual changes for the considered indices, the spatial patterns of the Multiyear Means (MM) for the first 30-year, i.e., 1961-1990, are superimposed to the multiyear means for the second 30-year period, i.e., 19892018 as shown on Fig. 1. Such comparison is acceptable, hence the both periods overlaps in only two years. The long-term changes are estimated by means of the relative bias, i.e., the difference between the MMs for the second and first period in respect to the first period.

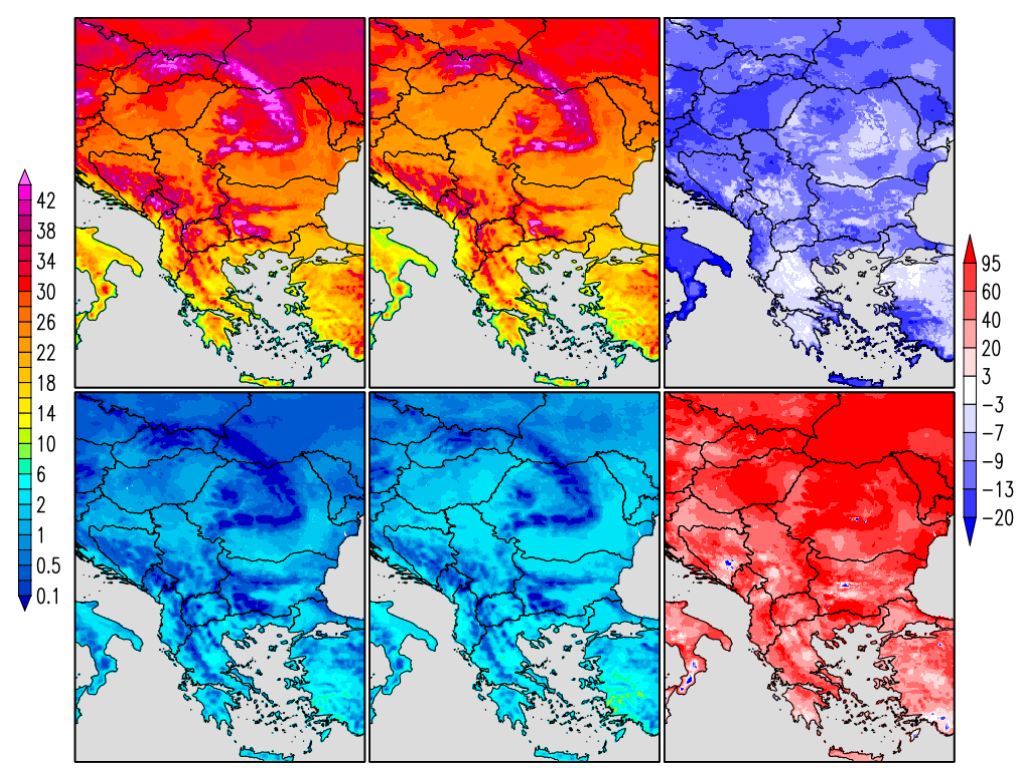

Fig. 1. Multiyear means of HDD (first row) and CDD (second row) in the first and second column correspondingly for 1961-1990 and for 1989-2018. The units are $100{ }^{\circ} \mathrm{D}$. The relative biases (in \%) are shown in the third column

The spatial patterns of the variables considered are generally consistent in both time spans. The vertical gradients are reproduced in detail that is direct consequence from the high grid spacing. The landscape of CSE Europe contains large plains, high 
mountains, mountain chains and fragmented coastlines and is quite non-uniform. The exploitation of datasets with coarser grid spacing could lead to overlooking of local spatial details, essential for some end-user applications. As stated in the regional study [6], based on the $0.1^{\circ} \times 0.1^{\circ}$ dataset CARPATCLIM [22], the regional differences in the HDD and CDD trends within the considered domain are related more to altitude, rather than latitude.

The most obvious result from the analysis of Fig. 1 is the substantial decrease of the HDD and, vice versa, increase of CDD over the entire domain. Both biases are quite uniform and the relative increase of the CDD is significantly higher than the decrease of the HDD. Some recent papers (e.g., [6, 9-11, 16, 17]) have noted the asymmetrical evolution patterns of the regional warming in the near past but depending of the considered input data, time span and methodology the different studies have yielded mixed results.

The temporal evolution of the Area-weighted over land Averages (AA) of the HDD and CDD are shown on Fig. 2.

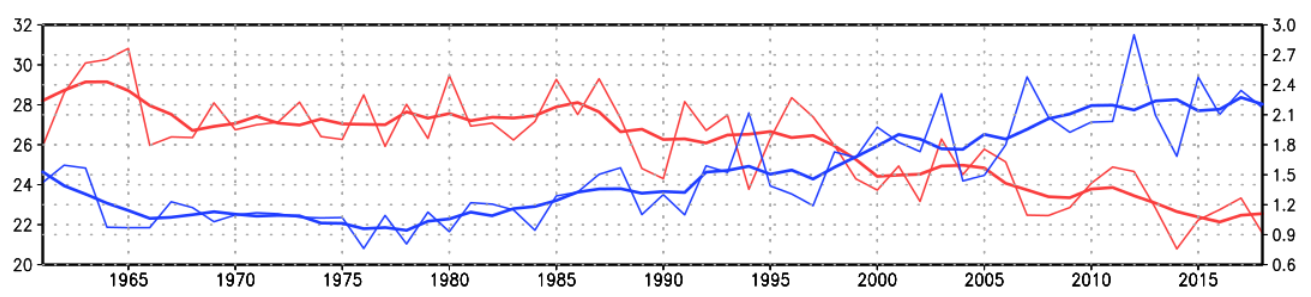

Fig. 2. Temporal evolution of the HDD (red line, left ordinate) and CDD (blue line, right ordinate). The units are $100^{\circ} \mathrm{D}$. The fat lines are the running 5-year means

In agreement with the results from the analysis of Fig. 1, the evolution of HDD and CDD shows fairly clear tendencies: Despite some colder episodes as, for example, the noted in [13] 1965, there is general decrease of the HDD and increase of the CDD. It is worth to emphasize also that the inter-annual course of the HDD is somewhat anti-correlated with the inter-annual course of the CDD. This is reflection of the fact that generally warm years are characterized most frequently with low values of HDD and high CDD and vice versa.

\subsection{Trend analysis}

The magnitude of the trend is estimated by the Theil-Sen Estimator (TSE), which is preferably used in many geophysical and engineering branches as a superior alternative of the ordinary least squares [8]. The statistical significance is analysed with the Mann-Kendall (MK) test. As, like the TSE, the MK test is non-parametric, rank-based procedure has been applied, especially suitable for non-normally distributed data, data containing outliers and nonlinear trends [6]. Both methods are practically standard tools for trend analysis in the climatology. In the present study they are applied for every grid point time series individually. In the present work, as in many similar studies (e.g., $[6,9-12,26]$ ) the significance level is fixed at 5\% (twotail test). 


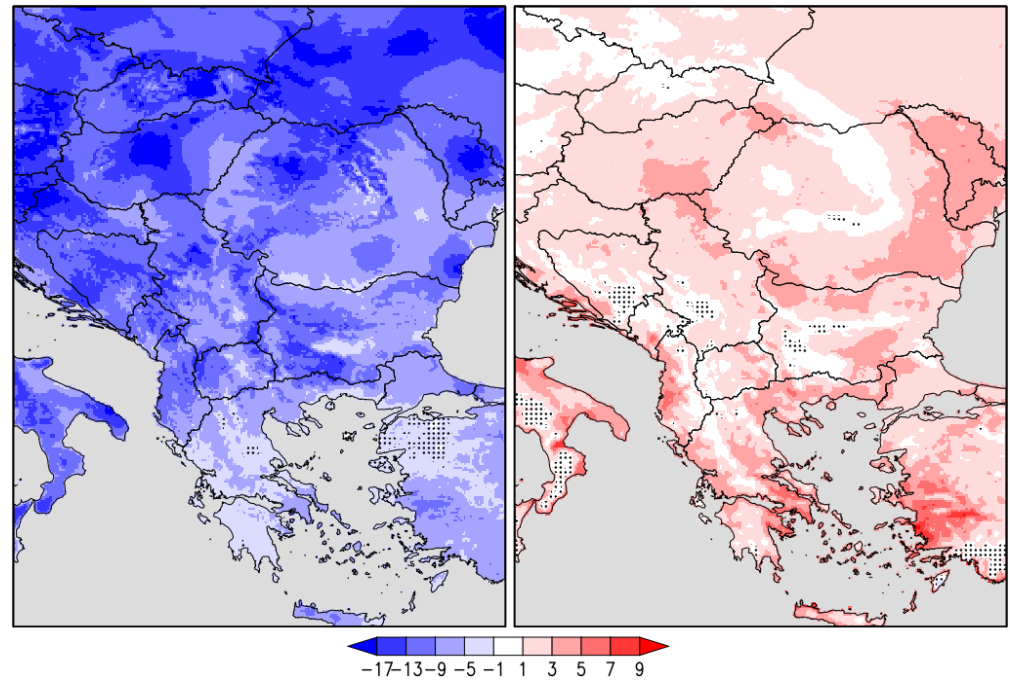

Fig. 3. Trend magnitude of the HDD and CDD in the first and second column respectively. The units are ${ }^{\circ} \mathrm{D}$ per 1 year. Stippling indicates grid points with changes that are not significant at the $5 \%$ significance level

The most apparent result from the analysis of Fig. 3 is the markedly expressed negative trend for the HDD and positive trend for the CDD. The trends magnitude of the HDD is, in absolute terms and as a whole, bigger than the trend magnitude of the CDD. The trends of the both indices are practically everywhere statistically significant at the 5\% and their patterns are consistent over the domain, i.e., there are no mixed trends for both indices.

\section{Conclusion}

Based on the availability of up to date dataset [12] based on the primary data from the FP7 UERRA project, we provide an overview of the spatial patterns in very high resolution and the long term temporal evolution on annual basis of the HDD and CDD over CSE Europe in the period 1961-2018.

The study confirms the suitability of the considered dataset for index-based analysis of the near past and present climate in computationally feasible way as has been already shown in [13].

Although not fairly exhaustive, the study confirms the essential impact of the ongoing climate change on the heating, ventilating and air-conditioning industry over CSE Europe. Consistent with the long-term changes of the mean and extreme temperatures over the domain, documented in the most recent papers, the present study reveals strong evidences for the impact of the regional climate warming on the considered indices. As emphasized in [18], a decrease in the demand for public and domestic heating can significantly decrease overall energy use in Europe, but this gain can be offset in part or completely by an increase in cooling demand. Furthermore, heating is delivered to end users in different ways (individual boilers fuelled by oil, gas and coal, and electricity and district heating), whereas cooling is 
supplied currently almost exclusively through electricity. As a result, a given change in cooling needs is generally associated with larger costs, a larger change in primary energy demand and larger impacts on the peak capacity of supply networks than the same change in heating requirements.

The study could be extended and continued in many aspects. The logical next step is to accomplish the work assessing the future changes and trends based on (preferably regional) climate simulations. Hence, the temperatures in all CMIP5 scenarios are projected to rise further, it is reasonable to expect additional decrease of the HDD and increase of CDD. Our preliminary computations with the regional climate model RegCM confirm this assumption. The study could also be extended backwards in time as far as possible in order to capture more general and robust trends. A necessary prerequisite for such task, however, is, as for many other efforts in the regional climatology, the (free) availability of reliable data with proper spatial coverage and spatial-temporal resolution.

The data sets with the HDD and CDD, as well as the trend measures (TSE trend magnitude estimation and $p$-value from the MK test) are in standard form (GrADS binary/descriptor files) and could be supplied from the corresponding author upon request.

Acknowledgments: This work is based on UERRA (EU FP7 Collaborative Project, Grant Agreement 607193). Hence this study entirely exploits free available data and software, the authors would like to express their deep gratitude to the organizations and institutions (UERRA Project, CARPATCLIM, MPI-M, UNI-DATA, Copernicus Data Store), which provides free of charge software and data.

This work has been carried out in the framework of the National Science Program "Environmental Protection and Reduction of Risks of Adverse Events and Natural Disasters", approved by the Resolution of the Council of Ministers № 577/17.08.2018 and supported by the Ministry of Education and Science (MES) of Bulgaria (Agreement № Д01-322/18.12.2019).

This work has been accomplished with the financial support by the Grant No BG05M2OP0011.001-0003, financed by the Science and Education for Smart Growth Operational Program (2014-2020) and co-financed by the European Union through the European structural and Investment funds.

\section{References}

1. A 1 e x a n d e r, L.V., et al. Global Observed Changes in Daily Climate Extremes of Temperature and Precipitation. - J. Geophys. Res., Vol. 111, 2006, No D5. DOI: 10.1029/2005jd006290.

2. A l e $x$ a n d rov, V., M. S c h n e i d e r, E. K o l e v a, J.-M. M o i s s e 1 i n. Climate Variability and Change in Bulgaria during the 20th Century. - Theor. Appl. Climatol., Vol. 79, 2004, pp. 133-149. https://doi.org/10.1007/s00704-004-0073-4

3. B a r th o ly, J., R. Pongrác z. Comparing Tendencies of Some Temperature Related Extreme Indices on Globaland Regional Scales. IDÖJÁRÁS, Vol. 110, 2006, pp. 35-48.

4. B a zil e, E., R. A bi d a, A. V e re 11 e, P. L e Moign e, C. S z c z y p t a. MESCAN-SURFEX Surface Analysis. Deliverable D2.8 of the UERRA Project. 2017. http://www.uerra.eu/publications/deliverable-reports.html

5. B e ld a, M., P. S k a lá k, A. F a rd a et al. CECILIA Regional Climate Simulations for Future Climate: Analysis of Climate Change Signal. - Advances in Meteorology, Vol. 2015, 2015, Article ID 354727. 13 p.

https://doi.org/10.1155/2015/354727 
6. B i r s a n, M.-V., A. D u m i tre s c u, D. M. M i c u, S. C h e v a l. Changes in Annual Temperature Extremes in the Carpathians since AD 1961. - Nat. Hazards, Vol. 74, 2014, No 3, pp. 1899-1910. https://doi.org/10.1007/s11069-014-1290-5

7. Buyukal a ca, O., H. Bulut, T. Y $11 \mathrm{maz}$. Analysis of Variable-Base Heating and Cooling Degree-Days for Turkey Applied Energy 69. 2001, pp. 269-283.

8. Chervenkov, H., K. S lavov. Theil-Sen Estimator vs. Ordinary Least Squares - Trend Analysis for Selected ETCCDI Climate Indices. - Compt. Rend. Acad. bulg. Sci., Vol. 72, 2019, No 1, pp. 47-54. https://doi.org/10.7546/CRABS.2019.01.06

9. $\mathrm{C} h$ e $\mathrm{r} v$ e $\mathrm{n} \mathrm{k}$ o v, H., K. S l a v o v. STARDEX and ETCCDI Climate Indices Based on E-OBS and CARPATCLIM. Part Two: ClimData in Use. - In: G. Nikolov et al., Eds. NMA 2018, LNCS 11189, 2019, pp. 368-374. DOI: 10.1007/978-3-030-10692-8 41.

10. C h e r v e n k o v, H., K. S l a v o v. Historical Climate Assessment of Temperature-Based ETCCDI Climate Indices Derived from CMIP5 Simulations. - Compt. rend. Acad. bulg. Sci., Vol. 73, 2020, No 6, pp. 784-790. https://doi.org/10.7546/CRABS.2020.06.05

11. C h e r v e $\mathrm{n} \mathrm{k} \mathrm{o} \mathrm{v,} \mathrm{H.,} \mathrm{K.} \mathrm{S} 1$ a v o v. ETCCDI Climate Indices for Assessment of the Recent Climate over Southeast Europe. - In: I. Dimov, S. Fidanova, Eds. Advances in High Performance Computing. HPC 2019. Studies in Computational Intelligence. Vol. 902. 2021, Cham, Springer. https://doi.org/10.1007/978-3-030-55347-0_34

12. Ch e rve n k o v, H., K. S l a vo v. Geo-Statistical Comparison of UERRA MESCAN-SURFEX Daily Temperatures Against Independent Data Sets. - IDÖJÁRÁS XXX (X) XX-XX (in Press).

13. Ch e rve n k o v, H., K. S l a v o v. Assessment of Agro-Meteorological Indices over Southeast Europe in the Context of Climate Change (1961-2018). - IDÖJÁRÁS XXX (X) XX-XX (in Press).

14. Cheval, S., M.-V. Birsan, A. Dumitrescu. Climate Variability in the Carpathian Mountains Region over 1961-2010. - Global and Planetary Change, Vol. 118, 2014, pp. 85-96. https://doi.org/10.1016/j.gloplacha.2014.04.005

15. CIBSE, Degree-Days: Theory and Application. Technical Manual 41. Chartered Institution of Building Services Engineers: London, UK. 2006. ISBN-10: 1-903287-76-6. http://www.degreedaysforfree.co.uk/pdf/tm41.pdf

16. Croit oru, A.-E., I.-H. Holobaca, C. Lazar, F. Moldovan, A. Imbroane. Air Temperature Trend and the Impact on Winter Wheat Phenology in RomaniaClimatic Change. Vol. 111, 2012, pp. 393-410. https://doi.org/10.1007/s10584-011-0133-6

17. D u m i t r e s c u, A., M. V. B i r s a n. ROCADA: A Gridded Daily Climatic Dataset over Romania (1961-2013) for Nine Meteorological Variables. - Nat. Hazards, Vol. 78, 2015, No 2, pp. 1045-1063.

https://doi.org/10.1007/s11069-015-1757-z

18. European Environment Agency, Heating and Cooling Degree Days, 2019. https://www.eea.europa.eu/data-and-maps/indicators/heating-degree-days-2/assessment

19. Gadzhev, G., I. Ge orgieva, K. Ganev, V. Ivanov, N. Miloshev, H. C h e r v e n k o v, D. S y r a k o v. Climate Applications in a Virtual Research Environment Platform. - Scalable Computing: Practice and Experience, Vol. 19, 2018, No 2, pp. 107-118. DOI 10.12694/scpe.v19i2.1347, ISSN: 1895-1767.

20. G a d z h e v, G., V. I v a n o v, R. V a l c h e v a, K. G a n e v, H. C h e r v e n k o v. HPC Simulations of the Present and Projected Future Climate of the Balkan Region. - In: I. Dimov, S. Fidanova, Eds. Advances in High Performance Computing. HPC 2019. Studies in Computational Intelligence. Vol. 902. 2021, Cham, Springer. https://doi.org/10.1007/978-3-030-55347-0_20 
21. J anković, A., Z. P odraščanin, V. Djurdjevic. Future Climate Change Impacts on Residential Heating and Cooling Degree Days in Serbia. - IDÖJÁRÁS Quarterly Journal of the Hungarian Meteorological Service, Vol. 123, July - September 2019, No 3, pp. 351-370.

22. L a k a to s, M., T. S z e n t i m r e y, Z. B i h a r i, S. S z a l a i. Investigation of Climate Extremes in the Carpathian Region on Harmonized Data. - In: Int. Scient. Conf. on Environmental Changes and Adaptation Strategies, September 2013, Temperature Thresholds and Crop Production: A Review.

23. Pongrácz, R., J. B a rtholy, G. Gelybó, P. S z abó. Detected and Expected Trends of Extreme Climate Indices for the Carpathian Basin. - In: K. Střelcová et al., Eds. Bioclimatology and Natural Hazards. Springer, Dordrecht, 2009.

https://doi.org/10.1007/978-1-4020-8876-6_2

24. P o n g rá c z, R., J. B a r th o l y, P. S z a b o, G. G e l y b ó. A Comparison of the Observed Trends and Simulated Changes in Extreme Climate Indices in the Carpathian Basin by the End of This Century. - Int. J. Global Warming, Vol. 1, 2009, Nos. 1/2/3, pp. 336-355.

https://doi.org/10.1504/IJGW.2009.027097

25. Ridal, M., S. S chimanke, S. Ho p s ch. Documentation of the RRA System: UERRA, Deliverable D322 Lot1.1.1.2 in the Scope of the Copernicus Service C3S 322 Lot1, 2018, Available via Copernicus.

26. S i 11 m a n n, J., E. R ö c k n e r. Climatic Change, Vol. 86, 2008, No 83. 10.1007/s10584-007-9308-6.

27. S o c i, C., E. B a zi l e, F. B e s s o n, T. L a n d e li u s. High-Resolution Precipitation Re-Analysis System for Climatological Purposes. - Tellus A: Dyn. Meteorology \& Oceanography, Vol. 68, 2016, No 1. https://doi.org/10.3402/tellusa.v68.29879

28. S p in o n i, J., J. V o g t, P. B a r b o s a. European Degree-Day Climatologies and Trends for the Period 1951-2011. - Int. J. Climatol., Vol. 35, 2015, pp. 25-36. DOI:10.1002/joc.3959.

29. S pinoni, J., J. V. Vogt, P. B arbosa, A. Dosio, N. Mc Cormick, A. Bigano, H. M. F ü s s e 1. Changes of Heating and Cooling Degree-Days in Europe from 1981 to 2100. - Int. J. Climatol, Vol. 38, 2018, pp. e191-e208. DOI:10.1002/joc.5362.

30. U n d e n, P. UERRA: Final Report, Project No: 607193, 2018. Period Number: 3rd Ref: 607193 UERRA Final Report-13 20180319112103 CET.pdf

Received: 15.09.2020; Second Version: 21.10.2020; Accepted: 23.10.2020 